\title{
Molecular Diversity of Wheat (Triticum aestivum L.) Genotypes Resistance to Rice Weevil (Sitophilus oryzae L.) Revealed by SSR Markers
}

\author{
Ekhlaque Ahmad $^{1,2} *$, Saurabh Badoni ${ }^{1}$, Moin Akhtar ${ }^{1}$ and J.P. Jaiswal ${ }^{1}$ \\ ${ }^{1}$ Department of Genetics and Plant Breeding, G. B. Pant University of Agriculture and \\ Technology, Pantnagar-263145 (Uttarakhand), India \\ ${ }^{2}$ Zonal Research Station (Birsa Agricultural University), Chianki, Palamau-822102, India \\ *Corresponding author
}

\section{A B S T R A C T}

The present investigation was carried out to analyse for the presence of $\alpha$-amylase inhibitor gene which is responsible for resistance to rice weevil. A total of 30 simple sequence repeat (SSR) markers were used to study the genetic diversity among 30 wheat genotypes resistant to rice weevil. Among them, seventeen primers were found polymorphic on agarose gel and depicted the significant diversity among susceptible and resistant genotypes while rest thirteen primers were found monomorphic. The number of

\section{Keywords}

Wheat (Triticum aestivum L.), Molecular diversity, SSR marker, Weevil resistance

Article Info

Accepted: 06 June 2018 Available Online: 10 July 2018 polymorphic bands per loci ranged from 1 to 3 with an average of 1.6 alleles per locus. A clear cut differentiation was exhibited among the genotypes. The average PIC value was 0.37 ranging from 0.17 (WMC120/ WMC76/WMC245) to 0.67 (WMC267), indicating diverse nature of the wheat genotypes and/or highly informative SSR markers used in this study. The analyzed wheat genotypes showed a good level of genetic variability for assessed quantitative, physio-chemical and molecular characters. Molecular markers linked with major genes for traits of interest which have been amplified by the primer set UCW108, a genic marker for GPC-B1. The range of similarity coefficient varied from 54\% (PBN-51) to 74\% (K 20). SAHN cluster analysis using UPGMA method separated the parental genotypes into four cluster groups, PBN 51 was positioned as single genotype in separate groups i.e., in cluster-I, K 50, K 76 and K 77 in cluster-II, K $2 \mathrm{I}$ and $\mathrm{K} 50$ in cluster-III and K 20 in cluster-IV. In dendrogram, based on results of markers validated were able to diversify the resistant and susceptible parents, first group member PBN51 and fourth group member K20 found on the two distant groups, which were observed as most susceptible and resistant genotypes respectively, according to our controlled experiment on weevil infestation and molecular analysis done and hence, the study supports and correlates the result, obtained by these analysis. The present study also indicates that microsatellite markers able to access the genetic diversity among studied genotypes of wheat for weevil resistance. 


\section{Introduction}

Wheat is second most important cereal crop after rice and is widely grown almost all over the world. India ranks second in production after China with a production of 97.44 million tonnes from an area 30.72 million hectare during 2016-17 (Anonymous, 2017). Phenomenal increase in wheat production and productivity has been achieved with the advent of high yielding improved varieties. One of the most important reasons for this success has been the relatively pest free field conditions of wheat. Producers should consider varietal suitability for long term storage when selecting crop varieties. Farmers keep their produce in homemade storage primarily to increase the net value of the crop selling when prices are more favourable. However, grain price is determined in part by test weight, absence of insects and damage caused by insects. Wheat is quite susceptible to storage pests which cause substantial qualitative (nutritional) and quantitative losses of various magnitudes depending on the pest species and duration of storage (Singhamony et al.1985). In Indian subcontinent, however wheat is heavily infested by a number of insect pests in storage, among these, Sitophilus oryzae (L.), Rhizopertha dominica (F.) and Trogoderma granarium Everts. are most important. Insect-pests which feed mainly on crops causes 10 to $30 \%$ damage in both traded and elevator stored grains every year (Karunakaran et al., 2004). It is estimated that $5-10 \%$ of world's grain production is lost due to ravages of insects. The losses may reach up to $50 \%$ in tropical countries where summer is hot and humid and storage facilities are improper and inadequate (Ahmad and Ahmad, 2002). The rice weevil is a pest of economic importance causing losses in weight, deterioration of quality and facilitating the development of micro-organisms in stored cereals.
Unfortunately, wheat varieties are not developed for their ability to resist insect attack at postharvest. Yield, adaptability to specific growing conditions, quality parameters and resistance to diseases and postharvest insect-pest infestation are the main breeding objectives in wheat. Due to increasing threat of insect-pests in storage particularly rice weevil, there is a need for understanding the various dimensions of its resistance to breed the resistant genotypes. However, the major hindrance in utilizing the resistance against the pest is that resistant source is scanty. Also the nature of resistance is still not very clear. Therefore, the success of the breeding programme lies in the identification of source of resistant genes and sound knowledge of genetic behaviour of the resistant genes. In this concern knowledge of genetic diversity in a crop species is fundamental to its improvement. The Polymerase Chain Reaction (PCR) based molecular markers such as RAPD, SSR and ISSR have successfully been utilized to assess the genetic diversity among the genotypes of several crop plants. Out of these, SSR are highly informative and locus specific genetic markers which are co-dominant in nature with high information content (Danin-Poleg et al., 2000). SSR has facilitated the studies of genetic diversity (Plaschke et al., 1995), gene mapping (Pestsova et al., 2002) and testing of authenticity of genetic stocks (Pestsova et al., 2002). Microsatellite markers have high potential for use in studies regarding genetic diversity and relationships. Keeping the usefulness of resistant genes in view, the present investigation was carried out with microsatellite (SSR) markers for analysis of genetic diversity of 30 genotype of wheat for rice weevil resistance.

\section{Materials and Methods}

PCR based Molecular diversity work was carried out at Wheat Grain Quality 
Laboratory, Department of Genetics and Plant Breeding, G. B. Pant University of Agriculture and Technology, Pantnagar in the year 201112 using microsatellite markers. Parents and their progenies were subjected to molecular marker analysis for the presence of $\alpha$-amylase inhibitor gene information on the basis of in vitro experiments.

\section{Plant materials}

The materials used in the investigation comprised of 30 accessions of wheat genotypes resistant to Sitophilus oryzae based on invitro experiment have been for depicted in Table 1. Each accession was sown in pots and leaf sample from 2-3 week old seedlings were collected for genomic DNA isolation.

\section{Genomic DNA extraction and quantification}

Freshly collected leaf sample of each genotype was ground to fine powder in mortar and pestle using liquid nitrogen and immediately it was processed using the Plant Genomic DNA isolation kit (HiMedia Laboratories Pvt. Ltd, India). The kit was especially designed for plant genomic DNA isolation and based on Cetyl Trimethyl Ammonium Bromide (CTAB) method. The RNA content in genomic DNA isolated using the kit was removed using RNase A. Quantity and quality of the genomic DNA was determined using dual beam spectrophotometer (Systronics, India) and Agarose gel electrophoresis (Sambrook and Russel, 2001).

\section{DNA markers}

Polymerase chain reaction (PCR) based marker SSR was used to quantify the genetic diversity of the wheat. A total of 30 SSRs were used in the investigations which have been depicted in Table 2.

\section{PCR amplification}

PCR amplification was performed in a volume of $25 \mu \mathrm{l}$. Each $25 \mu \mathrm{l}$ reaction mixture consisted of $100 \eta \mathrm{g}$ of DNA, $200 \mu \mathrm{M}$ dNTPs, $1 \mathrm{U}$ of Taq polymerase, $1 \mathrm{X}$ Taq buffer and $1.2 \mu \mathrm{l}$ primer of SSR each of forward and reverse primers were used. Amplication reaction was performed with initial denaturation at $94{ }^{\circ} \mathrm{C}$ for $5 \mathrm{~min}$ followed by 35 cycles of denaturation at $94{ }^{\circ} \mathrm{C}$ and 30 second, annealing of primers for $1 \mathrm{~min}$ at $45-60{ }^{\circ} \mathrm{C}$ and polymerization for $1 \mathrm{~min}$ at $72{ }^{\circ} \mathrm{C}$. One cycle of final extension was maintained for $7 \mathrm{~min}$ at $72{ }^{\circ} \mathrm{C}$. Amplification reaction was performed in dual block DNA engine (Bio-Rad, USA). PCR amplified DNA fragments were resolved using 3\% Agarose gel for electrophoresis to resolve the fragments generated using SSR primers. The gels were stained with Ethidium bromide $(0.5 \mathrm{mg} / \mathrm{ml})$ and documented using Gel Documentation system (Alpha Imager $\mathrm{EC})$.

\section{Scoring of gel and analysis of data}

Each genotype was scored as presence (1) or absence (0) of respective allele against each primer. Pair wise Jaccard's similarity coefficients (1908) were calculated to determine the similarity of wheat genotypes. Unweighted pair group method with arithmetic average (UPGMA) based dendrogram was generated to determine marker based genetic relationship amongst the 30 genotypes. The data were analyzed using the NTSYS-pc software (Rohlf, 2000).

\section{Results and Discussion}

SSR markers are the markers of choice for variability studies in many crops as they are transferable, highly polymorphic, simple to interpret and they are multi-allelic and codominant (Rafaleski et al., 1996; Agrama and Tuinstra, 2003). This high level of 
polymorphism associated with SSR markers, is to be expected because of the unique mechanism responsible for generating SSR allelic diversity by replication slippage. Replication slippage is thought to occur more frequently than single nucleotide mutations and insertion/deletion events.

In wheat, abundant wheat genomic SSR markers are now available and have been mapped (Roder et al., 1998), making them a useful resource for further studies. Microsatellite markers are useful and becoming popular for different applications in wheat breeding due to their high level of polymorphism and easy handling (Gupta and Varshney, 2000) and are used to evaluate genetic diversity of hexaploid wheat (Triticum aestivum $\mathrm{L}$.)

Besides above weevil resistant specific primers additional thirty SSR primers were used for the analysis of genetic diversity of parental genotypes, in which some of the primers were tagged with particular traits. Among them seventeen primers were found polymorphic on agarose gel and depicted the significant diversity among susceptible and resistant genotypes while rest thirteen primers were found monomorphic. The number of polymorphic bands per loci ranged from 1 to 3 with an average of 1.6 alleles per locus. Similar type of result were also reported by Dong and Zeng (2003), Ravi et al., (2003), ZhongFu et al., (2003), Mahmood et al., (2004) and Medini et al., (2005).

Number of alleles/locus and PIC values for each SSR marker were calculated. The average PIC value was 0.37 ranging from 0.17
(WMC120/ WMC76/WMC245) to 0.67 (WMC267), indicating diverse nature of the wheat parental genotypes and/or highly informative SSR markers used in this study. PIC values suggest that SSRs employed in the present study resulted adequate and efficient. The analyzed wheat genotypes showed a good level of genetic variability for assessed quantitative, physio-chemical and molecular characters.

Similar types of results were revealed by XinMin et al., (2003), Roussel et al., (2004), Naghavi et al., (2004), Jian Cheng et al., (2007), Prasad et al., (2009), Zeb et al., (2009) and Najaphy et al., (2012). The detected genetic diversity for the six parental genotypes was lower than that of earlier reported by Salem et al., (2008) in wheat genotypes. Molecular markers linked with major genes for traits of interest are being routinely developed in several crops. Besides our specific objective, diversity showed by the parental lines might be due to others important morphological and physio-chemical tagged traits like protein content; which have been amplified by the primer set UCW108, a genic marker for GPC-B1 (Table 3-5).

Likewise the primer sets WMC 83 and WMC 149 were tagged to days to flowering, tillers number, grain yield, harvest index, spikelet per spike, days to flowering etc. Similar type of results in wheat have already been reported by earlier eminent workers, Huang et al., (2002), Gupta et al., (2003), Kuleung et al., (2004), Nicot et al., (2004), You et al., (2004), Stodart et al., (2005), Hayden et al., (2006), Roy et al., (2006), Malik et al., (2008), Iqbal et al., (2009) and Yildirim et al., (2011). 
Table.1 List of genotypes used for molecular study on the basis of invitro Experiment

\begin{tabular}{|c|c|c|c|}
\hline S.No & Generations & Pedigree & Weevil Infestation Reaction \\
\hline 1 & $\mathbf{P}_{1}$ & PBN51 & $\mathbf{S}$ \\
\hline 2 & $\mathbf{P}_{2}$ & K76 & $\mathbf{S}$ \\
\hline 3 & $\mathbf{P}_{3}$ & K77 & $\mathbf{S}$ \\
\hline 4 & $\mathbf{P}_{4}$ & K20 & $\mathbf{R}$ \\
\hline 5 & $\mathbf{P}_{5}$ & K21 & $\mathbf{R}$ \\
\hline 6 & $\mathbf{P}_{6}$ & K50 & $\mathbf{R}$ \\
\hline 7 & $F_{1} 1$ & PBN51 x K20 & $\mathbf{R}$ \\
\hline 8 & $F_{1} 4$ & PBN51 x K76 & $\mathbf{S}$ \\
\hline 9 & $F_{1} 5$ & PBN51 x K77 & $\mathbf{S}$ \\
\hline 10 & $F_{1} 9$ & K76 x K77 & $\mathbf{S}$ \\
\hline 11 & $\mathbf{F}_{\mathbf{1}} \mathbf{1 3}$ & K20 x K21 & $\mathbf{R}$ \\
\hline 12 & $F_{1} 14$ & K20 x K50 & $\mathbf{R}$ \\
\hline 13 & $F_{1} 15$ & K21 x K50 & $\mathbf{R}$ \\
\hline 14 & $F_{1} 6$ & K76 x K20 & $\mathbf{R}$ \\
\hline 15 & $F_{1} 7$ & K76 x K21 & $\mathbf{R}$ \\
\hline 16 & $F_{1} 8$ & K76 x K50 & $\mathbf{R}$ \\
\hline 17 & $\mathbf{F}_{2} \mathbf{1}$ & PBN51 x K20 & $\mathbf{R}$ \\
\hline 18 & $F_{2} 2$ & PBN51 x K21 & $\mathbf{R}$ \\
\hline 19 & $\mathbf{F}_{2} 7$ & K76 x K21 & $\mathbf{R}$ \\
\hline 20 & $\mathbf{F}_{2} 10$ & K77 x K20 & $\mathbf{R}$ \\
\hline 21 & $\mathrm{BC}_{1} 1$ & (PBN51 x K20)/PBN51 & $\mathbf{R}$ \\
\hline 22 & $\mathrm{BC}_{1} 11$ & $(\mathrm{~K} 77$ x K21)/K77 & $\mathbf{R}$ \\
\hline 23 & $\mathrm{BC}_{1} 13$ & $(\mathrm{~K} 20 \times \mathrm{K} 21) / \mathrm{K} 20$ & $\mathbf{R}$ \\
\hline 24 & $\mathrm{BC}_{1} 14$ & $(\mathrm{~K} 20 \times \mathrm{K} 50) / \mathrm{K} 20$ & $\mathbf{R}$ \\
\hline 25 & $\mathrm{BC}_{1} 15$ & $(\mathrm{~K} 21$ x K50)/K21 & $\mathbf{R}$ \\
\hline 26 & $\mathrm{BC}_{2} 3$ & $(\mathrm{PBN5} 1 \mathrm{x}$ K50)/K50 & $\mathbf{R}$ \\
\hline 27 & $\mathrm{BC}_{2} 7$ & $(\mathrm{~K} 76$ x K21)/K 21 & $\mathbf{R}$ \\
\hline 28 & $\mathrm{BC}_{2} 10$ & $(\mathrm{~K} 77$ x K20)/K 20 & $\mathbf{R}$ \\
\hline 29 & $\mathrm{BC}_{2} 13$ & $(\mathrm{~K} 20 \times \mathrm{K} 21) / \mathrm{K} 21$ & $\mathbf{R}$ \\
\hline 30 & $\mathrm{BC}_{2} 15$ & $(\mathrm{~K} 21 \times \mathrm{K} 50) / \mathrm{K} 50$ & $\mathbf{R}$ \\
\hline
\end{tabular}


Table.2 Seuences of the SSR Primers

\begin{tabular}{|c|c|c|c|c|}
\hline $\begin{array}{c}\text { S. } \\
\text { No. }\end{array}$ & Source Name & Forward primer Sequence $\left(5^{\prime}-3^{\prime}\right)$ & Reverse primer Sequence $\left(5^{\prime}-3^{\prime}\right)$ & $\begin{array}{c}\text { Annealing } \\
\text { Temperat } \\
\text { ure }\end{array}$ \\
\hline 1 & wmc25 & TCTGGCCAGGATCAATATTACT & TAAGATACATAGATCCAACACC & $45^{\circ} \mathrm{C}$ \\
\hline 2 & wmc35 & GCAGAGAGGCACAACTAGCGAG & AACCTTAAGGGTCTGCCGGAAC & $50{ }^{0} \mathrm{C}$ \\
\hline 3 & wmc76 & CTTCAGAGCCTCTTTCTCTACA & CTGCTTCACTTGCTGATCTTTG & $45^{\circ} \mathrm{C}$ \\
\hline 4 & wmc83 & TGGAGGAAACACAATGGATGCC & GAGTATCGCCGACGAAAGGGAA & $55^{\circ} \mathrm{C}$ \\
\hline 5 & wmc120 & GGAGATGAGAAGGGGGTCAGGA & CCAGGAGACCAGGTTGCAGAAG & $55^{0} \mathrm{C}$ \\
\hline 6 & wmc149 & ACAGACTTGGTTGGTGCCGAGC & ATGGGCGGGGGTGTAGAGTTTG & $55{ }^{0} \mathrm{C}$ \\
\hline 7 & wmc169 & TACCCGAATCTGGAAAATCAAT & TGGAAGCTTGCTAACTTTGGAG & $50{ }^{\circ} \mathrm{C}$ \\
\hline 8 & wmc170 & ACATCCACGTTTATGTTGTTGC & TTGGTTGCTCAACGTTTACTTC & $45^{0} \mathrm{C}$ \\
\hline 9 & wmc177 & AGGGCTCTCTTTAATTCTTGCT & GGTCTATCGTAATCCACCTGTA & $45{ }^{0} \mathrm{C}$ \\
\hline 10 & wmc243 & CGTCATTTCCTCAAACACACCT & ACCGGCAGATGTTGACAATAGT & $50^{\circ} \mathrm{C}$ \\
\hline 11 & wmc245 & GCTCAGATCATCCACCAACTTC & AGATGCTCTGGGAGAGTCCTTA & $50{ }^{\circ} \mathrm{C}$ \\
\hline 12 & wmc254 & AGTAATCTGGTCCTCTCTTCTTCT & AGGTAATCTCCGAGTGCACTTCAT & $45{ }^{0} \mathrm{C}$ \\
\hline 13 & wmc267 & $\begin{array}{l}\text { TCTTCACCCCATAATTGGAGAAG } \\
\text { ССТ }\end{array}$ & TGCTTATTCTGCGCACTGGATGCCTA & $55{ }^{0} \mathrm{C}$ \\
\hline 14 & $\operatorname{cfd} 15$ & CTCCCGTATTGAGCAGGAAG & GGCAGGTGTGGTGATGATCT & $60{ }^{\circ} \mathrm{C}$ \\
\hline 15 & $\operatorname{cfd} 24$ & GGCGCAATCTGAAAGAAAAG & CCAGGTCCCACTTTCGTCT & $60{ }^{\circ} \mathrm{C}$ \\
\hline 16 & $\operatorname{cfd} 26$ & TCAAGATCGTGCCAAATCAA & ACTCCAAGCTGAGCACGTTT & $60{ }^{\circ} \mathrm{C}$ \\
\hline 17 & $\operatorname{cfd} 30$ & AATCGCACAACAATGGTTCA & GCCTCTCCTCTCTGCTCCTT & $60{ }^{0} \mathrm{C}$ \\
\hline 18 & $\begin{array}{l}\text { UCW } 108(\mathrm{GPC}- \\
\mathrm{B} 1)\end{array}$ & AGCCAGGGATAGAGGAA & AGCTGTGAGCTGGTGTCCTT & $60{ }^{\circ} \mathrm{C}$ \\
\hline 19 & W24A & TCGTGGCGACACCCRTACCA & ACTCATTTGCTTGACTAGGC & $63{ }^{0} \mathrm{C}$ \\
\hline 20 & W47AT & AGTACGACGCATGGAGTAT & ACTCATTTGCTTGACTAGGC & $57{ }^{0} \mathrm{C}$ \\
\hline 21 & wmc167 & AGTGGTAATGAGGTGAAAGAAG & TCGGTCGTATATGCATGTAAAG & $45^{0} \mathrm{C}$ \\
\hline 22 & wmc44 & GGTCTTCTGGGCTTTGATCCTG & TGTTGCTAGGGACCCGTAGTGG & $50{ }^{0} \mathrm{C}$ \\
\hline 23 & wmc47 & GAAACAGGGTTAACCATGCCAA & ATGGTGCTGCCAACAACATACA & $50{ }^{0} \mathrm{C}$ \\
\hline 24 & wmc221 & ACGATAATGCAGCGGGGAAT & GCTGGGATCAAGGGATCAAT & $50{ }^{\circ} \mathrm{C}$ \\
\hline 25 & wmc93 & ACAACTTGCTGCAAAGTTGACG & CCAACTGAGCTGAGCAACGAAT & $60{ }^{0} \mathrm{C}$ \\
\hline 26 & wmc83 & TGGAGGAAACACAATGGATGCC & GAGTATCGCCGACGAAAGGGAA & $55{ }^{0} \mathrm{C}$ \\
\hline 27 & $\operatorname{cfd} 1$ & ACCAAAGAACTTGCCTGGTG & AAGCCTGACCTAGCCCAAAT & $60{ }^{0} \mathrm{C}$ \\
\hline 28 & $\operatorname{cfd} 2$ & GGTTGCAGTTTCCACCTTGT & CATCTATTGCCAAAATCGCA & $60{ }^{\circ} \mathrm{C}$ \\
\hline 29 & $\operatorname{cfd} 3$ & GCACCAACACACGGAGAAG & TTGAGAGGAGGGCTTGGTTA & $60{ }^{\circ} \mathrm{C}$ \\
\hline 30 & $\operatorname{cfd} 5$ & TGCCCTGTCCACAGTGAAG & TTGCCAGTTCCAAGGAGAAT & $60{ }^{\circ} \mathrm{C}$ \\
\hline
\end{tabular}


Int.J.Curr.Microbiol.App.Sci (2018) 7(7): $761-772$

Table.3 Analysis of SSR marker

\begin{tabular}{|c|c|c|c|c|c|}
\hline \multirow[t]{2}{*}{ S. No. } & \multirow[t]{2}{*}{ Primers Code } & \multirow{2}{*}{$\begin{array}{l}\% \\
\text { Polymorphism }\end{array}$} & \multicolumn{3}{|c|}{ Number of bands } \\
\hline & & & Total bands & $\begin{array}{l}\text { Monomorphic } \\
\text { Bands }\end{array}$ & $\begin{array}{l}\text { Polymorphic } \\
\text { Bands }\end{array}$ \\
\hline 1 & wmc25 & 66.67 & 12 & 4 & 8 \\
\hline 2 & wmc35 & 50 & 12 & 6 & 6 \\
\hline 3 & wmc76 & 83.33 & 12 & 2 & 10 \\
\hline 4 & wmc83 & 50 & 12 & 6 & 6 \\
\hline 5 & wmc120 & 33.33 & 12 & 8 & 4 \\
\hline 6 & wmc149 & 66.67 & 12 & 4 & 8 \\
\hline 7 & wmc169 & 50 & 12 & 6 & 6 \\
\hline 8 & wmc170 & 66.67 & 12 & 4 & 8 \\
\hline 9 & wmc177 & 66.67 & 12 & 4 & 8 \\
\hline 10 & wmc243 & 66.67 & 12 & 4 & 8 \\
\hline 11 & wmc245 & 83.33 & 12 & 2 & 10 \\
\hline 12 & wmc254 & 50 & 12 & 6 & 6 \\
\hline 13 & wmc267 & 66.67 & 12 & 4 & 8 \\
\hline 14 & cfd15 & 100 & 12 & 0 & 12 \\
\hline 15 & cfd 24 & 66.67 & 12 & 4 & 8 \\
\hline 16 & cfd26 & 50 & 12 & 6 & 6 \\
\hline 17 & $\operatorname{cfd} 30$ & 50 & 12 & 6 & 6 \\
\hline 18 & UCW 108(GPC-B1) & 50 & 12 & 6 & 6 \\
\hline 19 & W24A & 50 & 12 & 6 & 6 \\
\hline 20 & W47AT & 50 & 12 & 6 & 6 \\
\hline 21 & wmc167 & 83.33 & 12 & 2 & 10 \\
\hline 22 & wmc44 & 50 & 12 & 6 & 6 \\
\hline 23 & wmc47 & 66.67 & 12 & 4 & 8 \\
\hline 24 & wmc221 & 50 & 12 & 6 & 6 \\
\hline 25 & wmc93 & 33.33 & 12 & 8 & 4 \\
\hline 26 & wmc83 & 83.33 & 12 & 2 & 10 \\
\hline 27 & cfd1 & 50 & 12 & 6 & 6 \\
\hline 28 & cfd2 & 66.67 & 12 & 4 & 8 \\
\hline 29 & cfd3 & 50 & 12 & 6 & 6 \\
\hline 30 & cfd5 & 50 & 12 & 6 & 6 \\
\hline
\end{tabular}


Table.4 Estimated Jaccard's similarity coefficient of 30 genotypes of wheat using SSR data

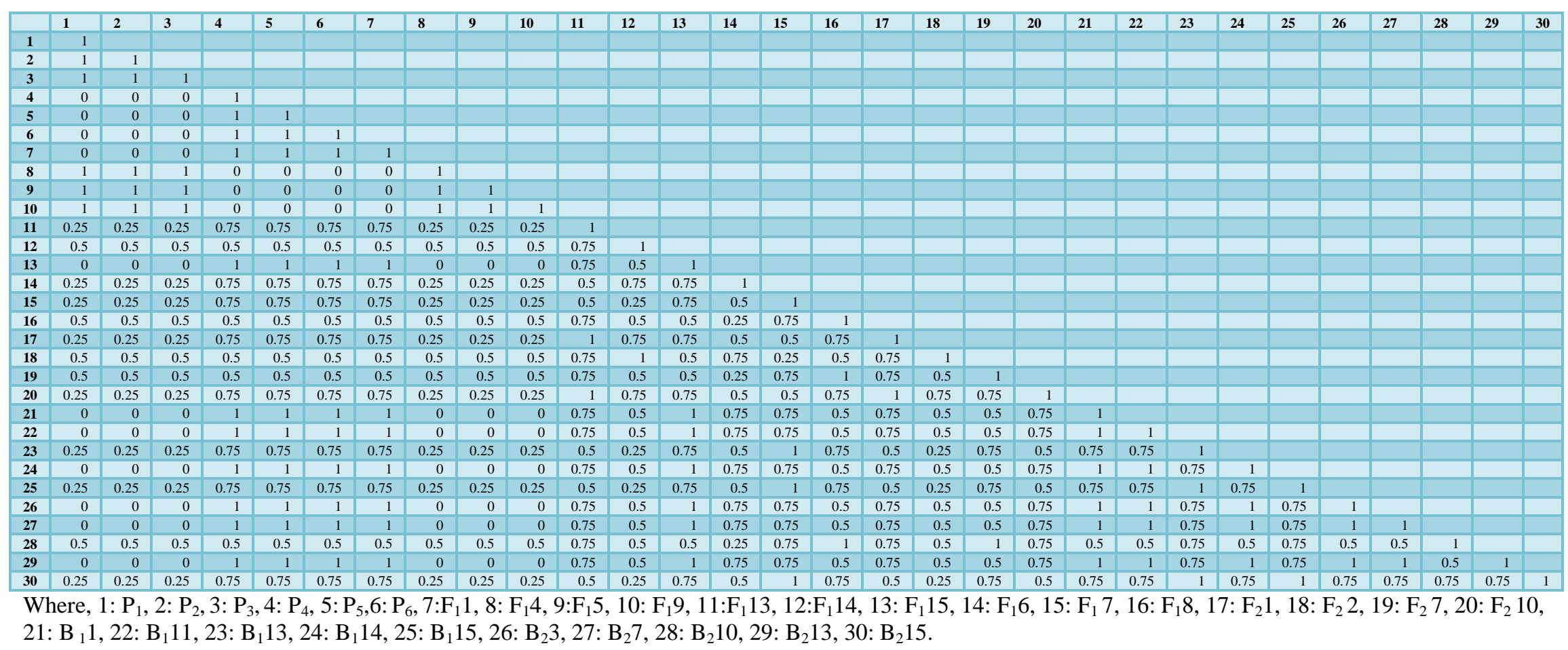

Table.5 Clustering group at $80 \%$ similarity level based on SSR using UPGMA dendrogram

\begin{tabular}{|l|l|l|}
\hline $\begin{array}{l}\text { Cluster } \\
\text { group }\end{array}$ & $\begin{array}{l}\text { No. of } \\
\text { genotypes }\end{array}$ & Name of genotypes \\
\hline I & 6 & $\mathrm{PBN} 51, \mathrm{~K} 76, \mathrm{~K} 77, \mathrm{PBN} 51 \times \mathrm{K} 76, \mathrm{PBN} 51 \times \mathrm{K} 77, \mathrm{~K} 76 \times \mathrm{K} 77$ \\
\hline II & 11 & $\begin{array}{l}\mathrm{K} 20, \mathrm{~K} 21, \mathrm{~K} 50, \mathrm{PBN} 51 \times \mathrm{K} 20, \mathrm{~K} 21 \times \mathrm{K} 50,(\mathrm{PBN} 51 \times \mathrm{K} 20) / \mathrm{PBN} 51,(\mathrm{~K} 77 \times \mathrm{K} 21) / \mathrm{K} 77,(\mathrm{~K} 20 \times \mathrm{K} \\
\mathrm{K} 50) / \mathrm{K} 20,(\mathrm{PBN} 51 \times \mathrm{K} 50) / \mathrm{K} 50,(\mathrm{~K} 76 \times \mathrm{K} 21) / \mathrm{K} 21,(\mathrm{~K} 20 \times \mathrm{K} 21) \mathrm{K} 21\end{array}$ \\
\hline III & 1 & $\mathrm{~K} 76 \times \mathrm{K} 20$ \\
\hline IV & 3 & $\mathrm{~K} 20 \times \mathrm{K} 21, \mathrm{PBN} 51 \times \mathrm{K} 20, \mathrm{~K} 77 \times \mathrm{K} 20$ \\
\hline V & 2 & $\mathrm{~K} 20 \times \mathrm{K} 50, \mathrm{PBN} 51 \times \mathrm{K} 21$ \\
\hline VI & 4 & $\mathrm{~K} 76 \times \mathrm{K} 21,(\mathrm{~K} 20 \times \mathrm{K} 21) / \mathrm{K} 20,(\mathrm{~K} 21 \times \mathrm{K} 50) / \mathrm{K} 21,(\mathrm{~K} 21 \times \mathrm{K} 50) / \mathrm{K} 50$, \\
\hline VII & 3 & $\mathrm{~K} 76 \times \mathrm{K} 50, \mathrm{~K} 76 \times \mathrm{K} 21,(\mathrm{~K} 77 \times \mathrm{K} 20) / \mathrm{K} 20$, \\
\hline
\end{tabular}


Fig.1 Dendrogram depicting the genetic relationship among 30 genotypes of different generations of wheat, constructed though UPGMA. Scale indicates the Jaccard's coefficient of genetic similarity. Where, 1: $\mathrm{P}_{1}, 2: \mathrm{P}_{2}, 3: \mathrm{P}_{3}, 4: \mathrm{P}_{4}, 5: \mathrm{P}_{5}, 6: \mathrm{P}_{6}, 7: \mathrm{F}_{1} 1,8: \mathrm{F}_{1} 4,9: \mathrm{F}_{1} 5,10: \mathrm{F}_{1} 9$, 11: $F_{1} 13,12: F_{1} 14,13: F_{1} 15,14: F_{1} 6,15: F_{1} 7,16: F_{1} 8,17: F_{2} 1,18: F_{2} 2,19: F_{2} 7,20: F_{2} 10,21: B$ ${ }_{1} 1,22: \mathrm{B}_{1} 11,23: \mathrm{B}_{1} 13,24: \mathrm{B}_{1} 14,25: \mathrm{B}_{1} 15,26: \mathrm{B}_{2} 3,27: \mathrm{B}_{2} 7,28: \mathrm{B}_{2} 10,29: \mathrm{B}_{2} 13,30: \mathrm{B}_{2} 15$

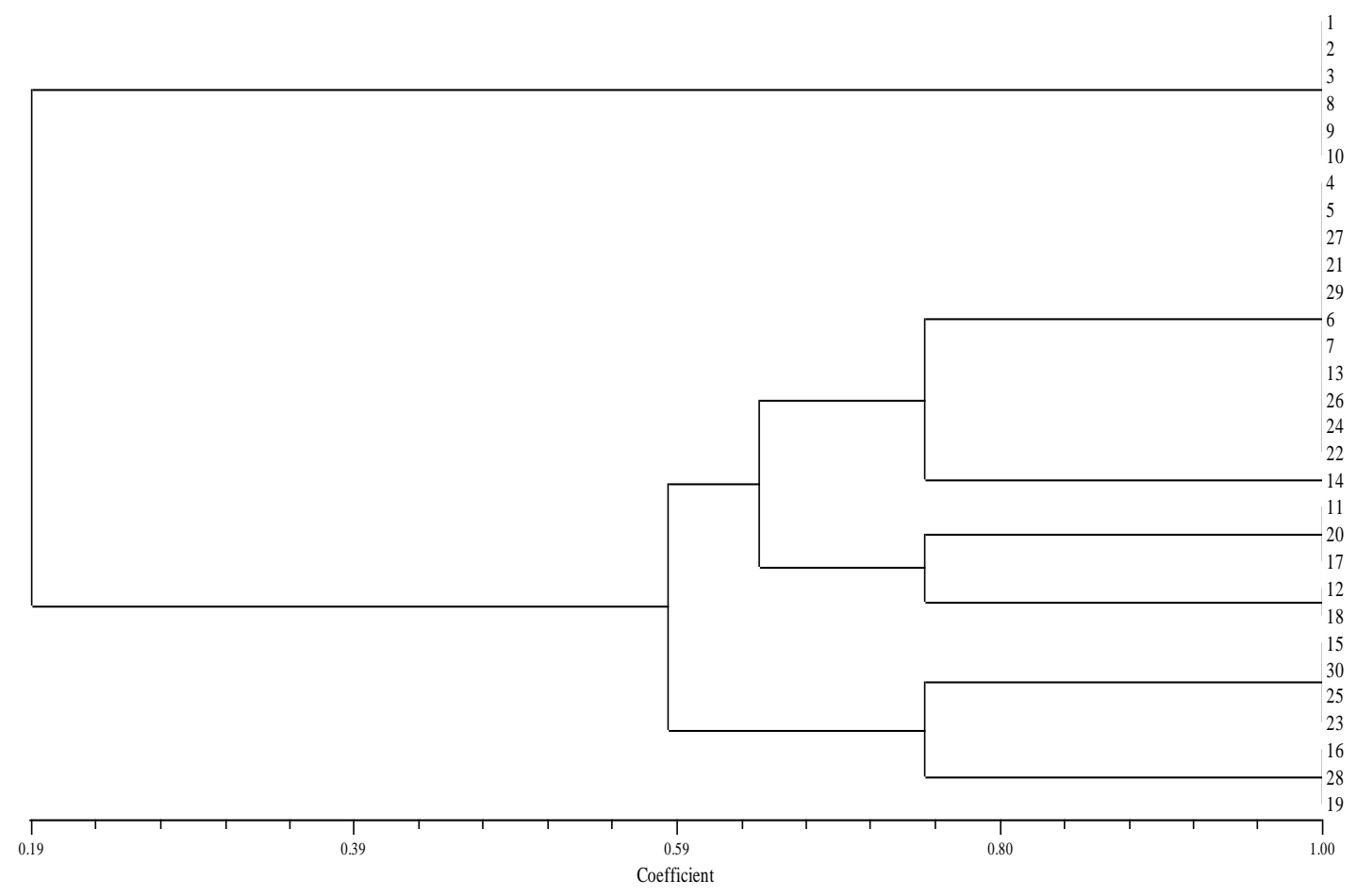

\section{Jaccard's similarity coefficient}

On the basis of SSR banding pattern provided by the 17 different primers, a dendrogram (Figure 1) based on Jaccard's similarity coefficient and UPGMA, was created. Range of coefficient varied from 0.54 to 0.74 . First group at a similarity coefficient ranged from 0.56 to 0.74 comprised of one genotype PBN 51. Second group at a similarity coefficient ranged from 0.59 to 0.74 comprised of $\mathrm{K} 21$, K50, K76 and K77 while third group at a similarity coefficient of 0.54 to 0.74 consisted of K20. In the dendrogram, K76 and K50 were found to be closely related genotypes, followed by K21 and K77. First group genotype PBN51 was found different from second group having four genotypes followed by third group genotype K20, which was found quite different from the rest 5 genotypes. Markers were able to diversify the resistant and susceptible parents. In dendrogram based on results of seventeen markers, first group member PBN51 and third group member K20 found on the two distant groups, which were observed as most susceptible and resistant genotypes respectively according to our controlled experiment on weevil infestation and molecular analysis done and hence, the study supports and correlates the result, obtained by these analysis. The results observed in this research are in agreement with those reported by Eivazi et al., (2008) and Izaj and Khan (2009).

\section{Acknowledgements}

Both authors are grateful to the Director Experiment Station, G. B. Pant University of 
Agriculture and Technology, Pantnagar for providing financial and infrastructural support to carry out the investigation. Leading author also extends his gracious gratitude to the Vice-Chancellor, Birsa Agricultural University, Ranchi for granting study leave under faculty development programme to pursue $\mathrm{PhD}$ degree.

\section{References}

Ahmad, M. and Ahmad, A., 2002, Storage of food grains. Farming Outlook 1: 1620.

Anonymous, 2017, Director's Report of AICRP on Wheat and Barley 2016-17. Ed: G.P. Singh. ICAR-Indian Institute of Wheat \& Barley Research, Karnal, Haryana, India. 2017, 87.

Agrama, H. A. and Tuinstra, M. R., 2003, Phylogenetic diversity and relationships among sorghum accessions using SSRs and RAPDs. African J. Biotech. 2: 334-340.

Danin-Poleg, Y., Reis, N., Baudracco-Arnas, S., Pitrat, M., Staub, J. E., Oliver, M., Arus, P., de Vicente, C.M. and Katzir, N., 2000, Simple sequence repeats in Cucumis, mapping and map merging. Genome 43: 963-974.

Dong, Z. Z. and Zeng, J. J., 2003,. Microsatellite marker development and applications in wheat genetics and breeding. Yichuan. 25(3): 355-360.

Eivazi, A. R., Naghavi, M. R., Hajheidari, M., Pirseyedi, S. M., Ghaffari. M. R., Mohammadi S. A., Majidi, I., Salekdeh, G. H. and Mardi, M., 2008, Assessing wheat (Triticum aestivum L.) genetic diversity using quality traits, amplified fragment length polymorphisms, simple sequence repeats and proteome analysis. Ann Appl Biol. 152: 81-91.

Gupta, P. K. and Varshney, R. K., 2000, The development and use of microsatellite markers for genetic analysis and plant breeding with emphasis on bread wheat. Euphytica 113(3): 163-185.

Gupta, P. K., Rustgi, S., Sharma, S., Singh, R., Kumar, N. and Balyan, H. S., 2003, Transferable EST-SSR markers for the study of polymorphism and genetic diversity in bread wheat. Molecular Genetics and Genomics 270(4): 315-323.

Huang, Q., Borner, A., Roder, S. and Ganal, W., 2002, Assessing genetic diversity of wheat (Triticum aestivum L.) germplasm using microsatellite markers. Theor. Appl. Genet. 105: 699-707.

Hayden, M. J., Stephenson, P., Logojan, A. M., Khatkar, D., Rogers, C., Elsden, J., Koebner, R. M. D., Snape, J. W. and Sharp, P. J., 2006, Development and genetic mapping of sequencetagged microsatellites (STMs) in bread wheat (Triticum aestivum L.). Theor. Appl. Genet. 113: 1271-1281.

Ijaz, S. and Khan, I. A., 2009, Molecular characterization of wheat germplasm using microsatellite markers. Genetics and Molecular Research 8(3): 809815.

Iqbal, N., Tabasum, A., Sayed, H. and Hameed, A., 2009, Evaluation of genetic diversity among bread wheat varieties and landraces of Pakistan by SSR markers. Cereal Research Communications 37(4): 489-498.

Jaccard, P., 1908, Nouvelles researches sur la distribution florale. Bul. Soc. Vaud. Sci. Nat. 44: 223-270.

JianCheng, L., Like, L., Ning, H., AiMin, Z. and ChunGuang, L., 2007, Genetic diversity of wheat gene pool of recurrent selection assessed by microsatellite markers and morphological traits. Euphytica 155(1/2): 249-258.

Karunakaran C., Janas D. S. and White N. D. 
G., 2004, Detection of internal wheat seed infestation by Rhyzopertha dominica F. using X-ray imaging. J. Stored Products Res. 40: 507-516.

Kuleung, C., Baenziger, P. S. and Dweikat, I., 2004, Transferability of SSR markers among wheat, rye and triticale. Theor. Appl. Genet. 108(6): 1147-1150.

Mahmood, A., Baenziger, P. S., Budak, H., Gill, K. S. and Dweikat, I., 2004, The use of microsatellite markers for the detection of genetic similarity among winter bread wheat lines for chromosome 3 A. Theor. Appl. Genet. 109: 1494-1503.

Malik, R., Chowdhury, V. K., Jain, S. and Jain, R. K., 2008, Microsatellites based genetic diversity analysis of Indian bread wheat genotypes. Env. and Eco. 26(1): 100-106.

Medini, M., Hamza, S., Rebai, A. and Baum, M., 2005, Analysis of genetic diversity in Tunisian durum wheat cultivars and related wild species by SSR and AFLP markers. Genetic Resources and Crop Evolution 52(1): 21-31.

Naghavi, M.R., Mardi, M., Ramshini, H. A. and Fazelinasab, B., 2004, Comparative analyses of the genetic diversity among bread wheat genotypes based on RAPD and SSR markers. Iranian J. Biotech., 2(3): 585-598.

Najaphy, A., Parchin, R. A. and Farshadfar, E. 2012. Comparison of phenotypic and molecular characterizations of some important wheat cultivars and advanced breeding lines. AJCS 6(2): 326-332.

Nicot, N., Chiquet, V., Gandon, B., Amilhat, L., Legeai, F., Leroy, P., Bernard, M. and Sourdille, P., 2004, Study of simple sequence repeat (SSR) markers from wheat expressed sequence tags (ESTs). Theor. and Appl. Genet.
109(4): 800-805.

Prasad, B., Babar M. A., Xu, X. Y., Bai, G. H. and Klatt, A. R., 2009, Genetic diversity in the U.S. hard red winter wheat cultivars as revealed by microsatellite markers. Crop Pasture Science 60: 16-24.

Pestsova, E., Ganal, M.W. and Roder, M. S., 2002, Isolation and mapping of microsatellite markers specified for the genome of bread wheat. Genome 43: 689-697.

Plaschke, J., Ganaland, M. W. and Röder, M. S., 1995, Detection of genetic diversity in closely related bread awheat using microsatellite markers. Theor. Appl.Gent. 91: 1001-1007.

Rafalski, J. A., Vogel, J. M., Morgante, M., Powell, W., Andre, C. and Tingey, S. V.. 1996, Generating and using DNA markers in plants. In: Birren B, Lai E (eds) Nonmammalian genomic analysis. A practical guide. Academic Press, San Diego, pp 75-134.

Ravi, M., Geethanjali, S., Sameeyafarheen, F. and Maheswaran, M., 2003, Molecular marker based genetic diversity analysis in rice (Oryza sativa L.) using RAPD and SSR markers. Euphy. 133: 243-252.

Roder, M. S., Korsun, V., Wendehake, K., Plaschke, J., Tixier, M. H., Leroy, P. and Ganal, M. W., 1998, A microsatellite map of wheat. Genetic, 149: 2007-2023.

Rohlf, F. J., 2000, NTSYS-pc: Numerical taxonomy and multivariate analysis system. Version 2.1 Exceter Software, New York, USA.

Roussel, V., Koenig, J., Beckert, M. and Balfourier, F., 2004, Molecular diversity in French bread wheat accessions related to temporal trends and breeding programmes. Theor. Appl. Genet. 108: 920-930.

Roy, J. K., Bandopadhyay, Rustgi, R. S., 
Balyan, H. S. and. Gupta, P. K., 2006, Association analysis of agronomically important traits using SSR, SAMPL and AFLP markers in bread wheat. Current Science 90(5): 683-389.

Salem, K. F. M., El-Zanaty, A. M. and Esmail, R. M., 2008, Assessing wheat (Triticum aestivum L.) genetic diversity using morphological characters and microsatallite markers. World J. Agril. Sci. 4(5): 538-544.

Singhamony, S., I. Anees, T. Chandrakala and Osman, Z., 1985, Efficacy of certain indigenous plants products as grain protectants against $S$. oryzae (L.) and $R$. dominica (F). Journal of Stored Products Research 22(10): 21-23.

Sambrook, J. and Russel, D. W., 2001, Molecular cloning: A laboratory manual. Cold Spring Harbor Laboratory Press, Cold Spring Harbor, New York.

Stodart, B. J., Mackay, M. and Raman, H., 2005, AFLP and SSR analysis of genetic diversity among landraces of bread wheat (Triticum aestivum L. em. Thell) from different geographic regions. Australian Journal of Agricultural Research 56(7): 691-697.

XinMin, C., ZhongHu, He., JanRong, Shi., LanQin, Xia., Ward, R., Zhou, Yang and Jiang, GuoLiang, 2003, Genetic diversity of high quality winter wheat varieties (lines) based on SSR markers. Acta Agronomica Sinica, 29(1): 13-19.

You, G. X., Zhang, X. Y. and Wang, L. F., 2004, An estimation of the minimum number of SSR loci needed to reveal genetic relationships in wheat varieties: Information from 96 random accessions with maximized genetic diversity. Molecular Breeding 14(4): 397-406.

Yildirim, A., Sonmezoglu, O. A., Gokmen, S., Kandemir, N. and Aydin, N., 2011, Determination of genetic diversity among Turkish durum wheat landraces by microsatellites. African Journal of Biotechnology 10(19): 3915-3920.

Zeb, B., Khan, I. M., Ali, S., Bacha, S., Mumtaz, S. and Swati, Z. A., 2009, Study on genetic diversity in Pakistani wheat varieties using simple sequence repeat (SSR) markers. African Journal of Biotechnology 8(17): 4016-4019.

Zhong, F. N., Zhang, Y. R., Liang, R. Q., Liu, G. T. and Sun, Q. X., 2003, Genetic diversity of $\mathrm{D}$-genome revealed by SSR markers in wheat (Triticum aestivum L.). Acta Agronomica Sinica 29(1): 145-151.

\section{How to cite this article:}

Ekhlaque Ahmad, Saurabh Badoni, Moin Akhtar and Jaiswal, J.P. 2018. Molecular Diversity of Wheat (Triticum aestivum L.) Genotypes Resistance to Rice Weevil (Sitophilus oryzae L.) Revealed by SSR Markers. Int.J.Curr.Microbiol.App.Sci. 7(07): 761-772. doi: https://doi.org/10.20546/ijcmas.2018.707.093 